\title{
High risk for HIV, syphilis, and risk behaviours among older female sex workers in Nepal
}

\author{
Sampurna Kakchapati ${ }^{1}$, Bhagawan Shrestha ${ }^{2}$, Ruthaychonnee Sittichai ${ }^{3}$, Apiradee Lim $^{1}$ \\ ${ }^{1}$ Faculty of Science and Technology, Prince of Songkla University, Pattani 94000, Thailand \\ ${ }^{2}$ Family Health International, Kathmandu, Nepal \\ ${ }^{3}$ Faculty of Humanities and Social Sciences and Research Center for Educational Innovations and Teaching and Learning \\ Excellence, Prince of Songkla University, Thailand
}

\begin{abstract}
Introduction: Older age is strong predictor of human immunodeficiency virus (HIV), syphilis, and risk behaviours among female sex workers (FSWs). Prior research suggests that age differences are very variable; HIV was higher among older FSWs. This study compares HIV, syphilis, and risk behaviours among younger and older FSWs of Nepal.

Material and methods: We conducted secondary analysis of Integrated Biological and Behavioural Surveillance (IBBS) surveys among FSWs from 2004 to 2016. Bivariate analysis using $\chi^{2}$ tests and multivariate logistic regression models were used to assess differences of HIV, syphilis, and risk behaviours among younger and older FSWs.

Results: The study comprised $17.6 \%$ FSWs aged 35 years or older. HIV prevalence was $1.7 \%$ for the entire group of FSWs, with $2.3 \%$ among older FSWs and $1.5 \%$ among younger FSWs. The older FSWs were married and separated, had lower education levels, had longer duration of sex work, worked on the streets, and had inconsistent condom used with clients than younger FSWs $(p<0.05)$. Younger FSWs were also at high risk because of a higher number of sexual partners and working days, pervasive alcohol consumption, and use of drugs $(p<0.05)$. The multivariate analysis revealed that older FSWs were more street-based $(\mathrm{aOR}=2.1,95 \% \mathrm{CI}=1.8-2.4)$, have inconsistent condom use with clients $(\mathrm{aOR}=1.8$, $95 \% \mathrm{CI}=1.4-2.1)$ and had higher syphilis rates $(\mathrm{aOR}=1.8,95 \% \mathrm{CI}=1.3-2.5)$ than younger FSWs.
\end{abstract}

Conclusions: Older FSWs practice higher risk behaviour and have higher syphilis prevalence. HIV and STI prevention interventions among targeting FSWs should consider risks and vulnerability of older FSWs.

Key words: HIV, syphilis, old age, Nepal.

\section{Introduction}

In Nepal, human immunodeficiency virus (HIV) prevalence among the adult population decreased from $0.34 \%$ in 2005 to $0.20 \%$ in 2015 , with an estimated 39,397 people living with HIV (PLHIV) in 2015. The country has made significant achievements in the reduction of new infections annually from 7512 in 2000 to 1331 in 2015, despite high HIV prevalence among people who inject drugs, men who have sex with men, and female sex workers [1].

Globally, female sex workers (FSW) are a high-risk group susceptible to acquiring HIV and sexually transmitted
Address for correspondence: Sampurna Kakchapati, Prince of Songkla University, Rusamlaie-4, 94000 Pattani, Thailand, phone: 977-9851139075,

e-mail: kck_sampurna@yahoo.com
Article history:

Received: 08.01.2017

Received in revised form: 24.10.2017

Accepted: 12.11.2017

Available online: 30.11 .2017
International Journal of HIV-Related Problems

HIV \& AIDS

R e v i e w 
infections (STIs) as well as transmitting the virus to others $[2,3]$. HIV infection among FSWs in Nepal differs by the epidemic typology and context of sex work setting (street and establishment). The most recent integrated biological and behavioural surveillance (IBBS) surveys conducted in Nepal provide evidence that FSWs in Nepal are increasing as more young females are coming into this profession when moving to cities in search of work [4-6]. Sex work in Nepal varies with different geographical setting and is more confined in cities such as Kathmandu and Pokhara and along the highway districts $[4,6]$. FSWs in Nepal are categorised into street based, establishment based, and home based, according to where the FSWs solicit their clients [4, 7-9]. Studies have found that street-based FSWs were at higher risk of unsafe sex, drug use, HIV, and STIs [7-9].

Studies have indicated that there is a variation of HIV risk behaviours among FSWs in different age groups [10, 11]. The available evidence suggests that older age ( $\geq 35$ years) is a potent predictor of HIV, syphilis, and risk behaviours among FSWs $[2,12,13]$. Older FSWs are considered as disadvantaged groups compared to their younger FSWs in the competitive sex world. They are likely to go on the street, accept clients who are at a high risk of HIV infection or transmission, or be willing to have unprotected sex for more money [14-16]. In contrast, other studies have also indicated that adolescent FSWs are of higher risk of sexual behaviours as compared to older peers [17-19]. Adolescent FSWs reported inconsistent condom use and lacked condom negotiation skills, low knowledge of HIV, and more anal sex and a greater number of customers per week, as compared to older FSWs [17-21].

Assessing HIV, syphilis and risk behaviours between FSWs of different age groups is of great importance for prevention. However, prevalence of HIV, syphilis, and behavioural risk factors among different age groups of FSWs remain under-studied in Nepal. Using data collected between 2004 and 2016 from the national Integrated Biological and Behavioural Surveillance (IBBS) surveys among FSWs from Kathmandu valley, Pokhara Valley, and highway districts, this paper aimed to compare the HIV-related risk behaviours among young and old FSWs in Nepal.

\section{Material and methods}

This study is based on secondary analysis of IBBS surveys among FSWs in Kathmandu Valley, Pokhara Valley and 22 Terai Highway Districts in Nepal from 2004 to 2016. The surveys were cross sectional in nature and some slight changes took place from one round to another, in order to remedy the weaknesses observed in previous rounds. Eligible FSWs were women aged 16 years and above who reported being paid in cash or kind for sex with a male within the last six months.

Two-stage cluster sampling method was employed to draw FSWs from the study sites in all rounds of IBBS surveys. IBBS surveys were taken in conformity with both ethical and human rights standards. Verbal informed and witnessed consent was obtained from all the FSWs prior to the interview and collection of blood samples. Study centres with laboratories/clinics were set up at easily accessible locations in all the study districts. Individual interviews, clinical examinations, and blood collections were carried out in separate rooms in each of the study centres. Blood samples were collected from all the FSWs and were tested for HIV and Syphilis. Ethical approvals for these surveys were obtained from the Nepal Health Research Council.

The independent variables for the study were background characteristics (year, region, education, marital status, type of sex work) and sexual behaviours (duration of sex work, age at first sexual contact, average number of clients, number of working days), consistent condom use with different sex partners, and injecting behaviours (the use of drugs, injecting practices). The sex partners of the FSW were categorised under clients, regular partners, and non-paying partners. Non-paying partners included boyfriends, husbands, and regular partners of the FSWs who did not compensate them for sexual services; while clients and regular partners included partners who paid them for sexual contact. The FSWs were divided into two age groups ( $<35$ years as younger FSW and $\geq 35$ years as older FSW) based on the definition of the age criterion of younger FSWs and older FSWs in previous surveys $[2,14,16]$. Chi-square test was performed to assess FSW's demographic information, sexual behaviours, drug injecting practices, HIV, and syphilis, by age group. Subsequently, multivariable logistic regression models were used to examine the difference between younger and older FSWs with HIV risk behaviours, HIV, and syphilis, while controlling for variables that were significant in the bivariate analyses. A p-value of less than 0.05 was used to determine statistical significance. Adjusted odd radios (AOR) and 95\% confidence intervals (95\% CI) were used to depict the independent relationship between predictors and dependent variables. $R$ program was used for statistical analysis.

\section{Results}

A total of 5958 FSWs were included in the analysis from 2004 to 2016, of whom $82.4 \%$ (4910) were under 35 years old and $17.6 \%$ (1048) were 35 years old and above. All variables were significantly associated with age ( $p$-value $<0.05$ ), as shown in Table 1 . Higher number of younger FSWs were found more in Kathmandu Valley (45\%) and Pokhara Valley (17\%) whereas older FSWs were found more in the Terai region (57\%). Likewise, younger FSWs mostly worked in an establishment setting (62\%) and older FSWs worked more on the streets (59\%). Older FSWs were significantly less educated than younger FSWs. The majority of older FSWs (59\%) were illiterate whereas 29\% of younger FSWs had no education. There were significant group differences in marital status; younger FSWs (29\%) were more likely to be single than older FSWs (11\%). Older FSWs were more often married (58\% vs. $45 \%)$ and sepa- 
Table 1. Comparison of background characteristics among young and older female sex workers (FSWs)

\begin{tabular}{|c|c|c|c|c|c|}
\hline \multirow[t]{2}{*}{ Characteristics } & $\begin{array}{c}\text { Total } \\
(N=5958)\end{array}$ & $\begin{array}{c}\text { Young FSWs } \\
<35 \text { years } \\
(n=4910,82.4 \%)\end{array}$ & $\begin{array}{c}\text { Older FSWs } \\
\geq 35 \text { years } \\
(n=1048,17.6 \%)\end{array}$ & \multirow[t]{2}{*}{$\chi^{2}(d f)$} & \multirow[t]{2}{*}{$p$-value } \\
\hline & $N(\%)$ & $n(\%)$ & $n(\%)$ & & \\
\hline \multicolumn{4}{|l|}{ Year } & \multirow{8}{*}{ 295(7) } & \multirow{8}{*}{$<0.001$} \\
\hline 2004 & $700(11.7)$ & $625(12.7)$ & $75(7.2)$ & & \\
\hline 2006 & $1300(21.8)$ & $1116(22.7)$ & $184(17.6)$ & & \\
\hline 2008 & $700(11.7)$ & $625(12.7)$ & $75(7.2)$ & & \\
\hline 2009 & $600(10.1)$ & $495(10.1)$ & $105(10)$ & & \\
\hline 2011 & $938(15.7)$ & $847(17.3)$ & $91(8.7)$ & & \\
\hline 2012 & $610(10.2)$ & $449(9.1)$ & $161(15.4)$ & & \\
\hline 2015 & $500(8.4)$ & $351(7.1)$ & $149(14.2)$ & & \\
\hline 2016 & $610(10.2)$ & $402(8.2)$ & $208(19.8)$ & & \\
\hline \multicolumn{4}{|l|}{ Region } & \multirow{4}{*}{$143(2)$} & \multirow{4}{*}{0.002} \\
\hline Kathmandu & $2593(43.5)$ & $2232(45.5)$ & $361(34.4)$ & & \\
\hline Pokhara & 945 (15.9) & $852(17.4)$ & $93(8.9)$ & & \\
\hline Terai & $2420(40.6)$ & $1826(37.2)$ & $594(56.7)$ & & \\
\hline \multicolumn{4}{|l|}{ Place of work } & \multirow{3}{*}{$157(1)$} & \multirow{3}{*}{$<0.001$} \\
\hline Establishment & $3502(58.8)$ & $3068(62.5)$ & $434(41.4)$ & & \\
\hline Street & $2456(41.2)$ & $1842(37.5)$ & $614(58.6)$ & & \\
\hline \multicolumn{4}{|l|}{ Education } & \multirow{4}{*}{$391(2)$} & \multirow{4}{*}{$<0.001$} \\
\hline No education & $2064(34.6)$ & $1440(29.3)$ & $624(59.5)$ & & \\
\hline Primary & $2146(36)$ & $1835(37.4)$ & $311(29.7)$ & & \\
\hline Secondary and above & $1748(29.3)$ & $1635(33.3)$ & $113(10.8)$ & & \\
\hline \multicolumn{4}{|l|}{ Marital status } & \multirow{4}{*}{$158(2)$} & \multirow{4}{*}{$<0.001$} \\
\hline Single & $1567(26.3)$ & $1454(29.6)$ & $113(10.8)$ & & \\
\hline Married & $2799(47)$ & $2195(44.7)$ & $604(57.6)$ & & \\
\hline Separated (widow/divorce) & $1592(26.7)$ & $1261(25.7)$ & $331(31.6)$ & & \\
\hline \multicolumn{4}{|l|}{ Duration of sex work } & \multirow{3}{*}{$460(1)$} & \multirow{3}{*}{$<0.001$} \\
\hline Less than 2 years & $3589(60.2)$ & $3267(66.5)$ & $322(30.7)$ & & \\
\hline More than 2 years & $2369(39.8)$ & $1643(33.5)$ & $726(69.3)$ & & \\
\hline
\end{tabular}

rated (32\% vs. $26 \%$ ) than younger FSWs. Duration of sex work was also associated with age: $69 \%$ of older FSWs had worked as a sex worker for more than two years compared to younger FSWs (33\%).

All variables were significantly associated with the age of FSWs except consistent condom use with non-paying partners and injecting drug practices, as shown in Table 2. Younger FSWs (96\%) had sexual debut at less than 20 years compared to older FSWs (91\%). Younger FSWs (91\%) had a significantly higher number of sexual partners than older FSWs (86\%). More younger FSWs (92\%) worked more than two days per week for sex work than older FSWs (88\%). There were significant differences in inconsistent condom use with clients and regular clients among younger and older FSWs. Older FSWs had higher inconsistent condom use with clients ( $23 \%$ vs. $12 \%)$ and regular clients
( $45 \%$ vs. $35 \%$ ) than younger FSWs. However, alcohol consumption and drug use were higher among younger FSWs than older FSWs. Younger FSWs consumed more alcohol (71\% vs. $66 \%)$ and used drugs ( $7 \%$ vs. $2 \%$ ) more than older FSWs.

Table 3 depicts the comparison of HIV and syphilis among younger and older FSWs. There was a significant difference of syphilis prevelance between the two groups. About $7 \%$ of older FSWs had syphilis compared to 3\% of younger FSWs. HIV prevalence was higher among older FSWs (2.3\%) than younger FSWs (1.5\%); however, there was no statistical association between age and HIV infection.

Table 4 shows the multivariate analyses of HIV risk behaviours among younger and older FSWs. Compared with younger FSWs, older FSWs were more likely to work on the street $(\mathrm{aOR}=2.1,95 \% \mathrm{CI}=1.8-2.5)$, have inconsistent 
Table 2. Comparison of sexual behaviours and drug injecting practices among young and older female sex workers (FSWs)

\begin{tabular}{|c|c|c|c|c|c|}
\hline \multirow[t]{2}{*}{ Characteristics } & $\begin{array}{c}\text { Total } \\
(n=5958)\end{array}$ & $\begin{array}{c}\text { Young FSWs } \\
<35 \text { years } \\
(n=4910,82.4 \%)\end{array}$ & $\begin{array}{c}\text { Older FSWs } \\
\geq 35 \text { years } \\
(n=1048,17.6 \%)\end{array}$ & \multirow[t]{2}{*}{$\chi^{2}(d f)$} & \multirow[t]{2}{*}{$p$-value } \\
\hline & $n(\%)$ & $n(\%)$ & $n(\%)$ & & \\
\hline \multicolumn{4}{|l|}{ Age at first sexual contact } & \multirow{3}{*}{$39(1)$} & \multirow{3}{*}{$<0.001$} \\
\hline Below 20 years & $5647(94.8)$ & $4695(95.6)$ & $952(90.8)$ & & \\
\hline Above 20 years & $311(5.2)$ & $215(4.4)$ & $96(9.2)$ & & \\
\hline \multicolumn{4}{|c|}{ Total number of sexual partners } & \multirow{3}{*}{$21(1)$} & \multirow{3}{*}{$<0.001$} \\
\hline Less than one & $573(9.6)$ & $432(8.8)$ & $141(13.5)$ & & \\
\hline More than one & $5385(90.4)$ & $4478(91.2)$ & $907(86.5)$ & & \\
\hline \multicolumn{4}{|l|}{ Number of clients per day } & \multirow{3}{*}{$91(1)$} & \multirow{3}{*}{$<0.001$} \\
\hline Less than one & $415(7)$ & $270(5.5)$ & $145(13.8)$ & & \\
\hline More than one & $5543(93)$ & $4640(94.5)$ & $903(86.2)$ & & \\
\hline \multicolumn{4}{|c|}{ Number of clients in past week } & \multirow{3}{*}{$41(1)$} & \multirow{3}{*}{$<0.001$} \\
\hline Less than one & $816(13.7)$ & $607(12.4)$ & 209 (19.9) & & \\
\hline More than one & $5142(86.3)$ & $4303(87.6)$ & $839(80.1)$ & & \\
\hline \multicolumn{4}{|c|}{ Number of working days in week } & \multirow{3}{*}{$20(1)$} & \multirow{3}{*}{$<0.001$} \\
\hline Less than two days & $513(8.6)$ & $385(7.8)$ & $128(12.2)$ & & \\
\hline More than two days & $5445(91.4)$ & $4525(92.2)$ & $920(87.8)$ & & \\
\hline \multicolumn{4}{|c|}{ Consistent condom used with clients } & \multirow{3}{*}{$87(1)$} & \multirow{3}{*}{$<0.001$} \\
\hline Yes & $5127(86.1)$ & $4321(88)$ & $806(76.9)$ & & \\
\hline No & $831(13.9)$ & $589(12)$ & $242(23.1)$ & & \\
\hline \multicolumn{4}{|l|}{$\begin{array}{l}\text { Consistent condom used } \\
\text { with regular partners }\end{array}$} & \multirow{3}{*}{$35(1)$} & \multirow{3}{*}{$<0.001$} \\
\hline Yes & $3755(63)$ & $3179(64.7)$ & $576(55.0)$ & & \\
\hline No & $2203(37)$ & $1731(35.3)$ & $472(45.0)$ & & \\
\hline \multicolumn{4}{|l|}{$\begin{array}{l}\text { Consistent condom use } \\
\text { with non-paying partners }\end{array}$} & \multirow{3}{*}{$0.4(1)$} & \multirow{3}{*}{0.579} \\
\hline Yes & $1217(20.4)$ & $1010(20.6)$ & $207(19.8)$ & & \\
\hline No & $4741(79.6)$ & $3900(79.4)$ & $841(80.2)$ & & \\
\hline \multicolumn{4}{|l|}{ Ever used alcohol } & \multirow{3}{*}{$16(1)$} & \\
\hline Yes & $3537(72)$ & $687(65.6)$ & $4224(70.9)$ & & $<0.001$ \\
\hline No & $1373(28)$ & $360(34.4)$ & $1733(29.1)$ & & \\
\hline Ever used drugs & & & & & \\
\hline Yes & $369(6.2)$ & $349(7.1)$ & $20(1.9)$ & $39(1)$ & $<0.001$ \\
\hline No & $5589(93.8)$ & $4561(92.9)$ & $1028(98.1)$ & & \\
\hline Ever injected drugs & & & & & \\
\hline Yes & $94(1.6)$ & $83(1.7)$ & $11(1)$ & $1.9(1)$ & 0.169 \\
\hline No & 5864 (98.4) & 4827 (98.3) & 1037 (99) & & \\
\hline
\end{tabular}

condom use with clients $(\mathrm{aOR}=1.8,95 \% \mathrm{CI}=1.4-2.1)$, and have syphilis $(\mathrm{aOR}=1.8,95 \% \mathrm{CI}=1.3-2.5)$. The risk of syphilis was nearly two times higher among older FSWs than younger FSWs. However, older FSWs were less likely to consume alcohol $(\mathrm{aOR}=0.7,95 \% \mathrm{CI}=0.6-0.8)$ and use drugs ( $\mathrm{aOR}=0.3,95 \% \mathrm{CI}=0.2-0.4)$ than younger FSWs.

\section{Discussion}

This is the first study to compare HIV risk behaviours among young and old FSWs in Nepal. The study found that compared to younger FSWs, older FSWs are more likely to have higher risk of syphilis. Moreover, older FSWs had 
Table 3. Comparison of HIV and syphilis among young and older female sex workers (FSWs)

\begin{tabular}{|c|c|c|c|c|c|}
\hline \multirow[t]{2}{*}{ Characteristics } & $\begin{array}{c}\text { Total } \\
(N=5958)\end{array}$ & $\begin{array}{c}\text { Young FSWs } \\
<35 \text { years } \\
(n=4910,82.4 \%)\end{array}$ & $\begin{array}{c}\text { Older FSWs } \\
\geq 35 \text { years } \\
(n=1048,17.6 \%)\end{array}$ & \multirow[t]{2}{*}{$\chi^{2}(d f)$} & \multirow[t]{2}{*}{$\mathrm{p}$-value } \\
\hline & $N(\%)$ & $n(\%)$ & $n(\%)$ & & \\
\hline \multicolumn{4}{|l|}{ Syphilis } & \multirow{3}{*}{ 28(1) } & \multirow{3}{*}{$<0.001$} \\
\hline Yes & $230(3.9)$ & $159(3.2)$ & $71(6.8)$ & & \\
\hline No & $5728(96.1)$ & $4751(96.8)$ & 977 (93.2) & & \\
\hline \multicolumn{4}{|l|}{ HIV } & \multirow{3}{*}{ 2.5(1) } & \multirow{3}{*}{0.117} \\
\hline Yes & $100(1.7)$ & $76(1.5)$ & $24(2.3)$ & & \\
\hline No & $5858(98.3)$ & 4834 (98.5) & $1024(97.7)$ & & \\
\hline
\end{tabular}

Table 4. Multivariate analyses of HIV risk among young and older female sex workers (FSWs)

\begin{tabular}{l|c|c|c|c|c|c}
\hline Age & $\begin{array}{c}\text { Street } \\
(\mathrm{aOR}, 95 \% \mathrm{Cl})\end{array}$ & $\begin{array}{c}\text { Inconsistent } \\
\text { condom use } \\
\text { with clients } \\
(\mathrm{aOR}, 95 \% \mathrm{Cl})\end{array}$ & $\begin{array}{c}\text { Inconsistent } \\
\text { condom use } \\
\text { with regular clients } \\
(\mathrm{aOR}, 95 \% \mathrm{Cl})\end{array}$ & $\begin{array}{c}\text { Alcohol } \\
\text { consumption } \\
(\mathrm{aOR}, 95 \% \mathrm{Cl})\end{array}$ & $\begin{array}{c}\text { Drug use } \\
(\mathrm{aOR}, 95 \% \mathrm{Cl})\end{array}$ & $\begin{array}{c}\text { Syphilis } \\
(\mathrm{aOOR}, 95 \% \mathrm{Cl})\end{array}$ \\
\hline Young & 1 & 1 & 1 & 1 & 1 & 1 \\
\hline Older & $2.1(1.8-2.4)^{\star * *}$ & $1.8(1.4-2.1)^{* * *}$ & $1.1(0.9-1.3)$ & $0.7(0.6-0.8)^{\star * *}$ & $0.3(0.2-0.4)^{\star * *}$ & $1.8(1.3-2.5)^{* * *}$ \\
\hline${ }^{* * *}$-value $<0.001$
\end{tabular}

longer duration of sex work, and had more unprotected sex with clients and regular clients compared to young FSWs. However, younger FSWs were also at higher risk of HIV and syphilis infection because of a greater number of sexual partners, higher number of working days for sex work, and pervasive alcohol consumption and drug use.

There existed an age difference with FSW in three regions of Nepal. Younger FSW were found more in Kathmandu Valley and Pokhara Valley, whereas older FSW were found more in the Terai Region. Younger FSWs were more confined to the urban and city areas of Nepal where they can work in an establishment setting and client solicitation is comparatively easy. Moreover, young clients with higher economic status prefer young FSWs and are ready to pay more money. Younger FSWs were more likely to be based in an establishment setting, and older FSWs were more likely to be based on the street for sex work. This may be because of the demand for young girls and women in an establishment setting due to the nature of the work and services offered by such an establishment. Furthermore, sex work can be done in a comparatively more clandestine and secure way in an establishment setting. As FSWs get older, they may not be able to continue working in an establishment setting because of the nature of work they have to do in the establishment setting, so they may move out to the street to continue sex work.

Older FSWs were more often married or separated than younger FSWs. Moreover, they were less educated than the younger FSWs. In the context of commercial sex, women who were divorced or widowed and with low education status may have had more financial pressure and may be in greater need of a livelihood as well as the ability to support their family, which may further make them prone to having unprotected sex for more money. Women who grew up in resource-poor settings usually lacked opportunities of education and skills training. Without job-related skills, these women may lack the opportunities to find alternative jobs and engage in sex work for their livelihood and to support their families $[2,13,15,16]$. With little or no formal education and few alternative employment opportunities, they tend to continue sex work for a longer duration [16]. Family responsibility, in combination with economic deprivation, lack of alternative options or jobs, and gender-based violence, were some of the driving forces propelling older women into sex work and encouraging them to engage in higher risk behaviours. In contrast, the majority of young FSWs were single and may not have had to take care of a family. These young FSWs work as sex workers due to peer pressure and for a quick and easy source of income for their personal needs and desires, and had less family responsibility [22,23].

Younger FSWs tended to serve a greater number of clients and have a greater number of working days per week for sex work. Some studies showed the existence of high-risk sexual behaviours among younger FSWs compared to older counterparts $[18,19]$. Adolescent FSWs had a high number of sex clients per week and had little knowledge of HIV $[18,19]$, and reported inconsistent condom use and less condom negotiation skill than their older FSWs [9]. Moreover, younger FSWs received more encouragement from their managers in the establishment setting to engage with a greater number of clients for money. 
Similar to findings from other studies, consistent condom use with clients and regular clients was lower among older FSWs than younger FSWs. Because older FSWs faced economic deprivation and family responsibility, they made every effort to solicit clients and did not want to lose their clients. Because of this, older FSWs may have little or no power to negotiate for condom use. If they insist on condom use, they might lose their clients. Confronted with the lure of money and economic difficulty of the family, their only choice would be to comply with their clients' request and have had sex without using condoms. Studies show that the majority of clients of older FSWs were older men. Older FSWs usually perceived older clients to be a lower risk for HIV infection and, consequently, did not use condoms. In addition, because of erectile dysfunction and ejaculation problems, older men often did not want to use condoms [16].

Alcohol use was prevalent among young FSWs. In Nepal, young FSWs mostly work in an establishment setting such as bars, dance and cabin restaurants, or hotel/lodge, so the employers/managers expect FSWs to drink and encourage customers to drink [23], and drinking alcohol with customers is part of their routine work so that customers spend more money and give tips to them. Besides this, FSWs also feel confident to deal with customers and perform their work, such as dancing, if they drink alcohol. Similarly, FSWs consume alcohol and use drugs to cope with the stress and violence associated with sex work [18, 24, 25]. Drug use was also higher among young FSWs than older FSWs. It was found that young FSWs have had sex under the influence of alcohol and drug use. Studies identified that inconsistent condom use with customers among young FSWs was influenced by their own as well as their customers' alcohol use $[14,26]$. Studies also suggested that FSWs are more likely to be HIV-infected if they injected drugs. The extent of HIV infection among FSWs is also determined in part by the overlapping risk of drug use and sex work.

Although HIV prevalence among FSWs was maintained below 2\% throughout 2004 and 2016, HIV prevalence was higher among older FSWs than young FSWs. This study found a relatively high prevalence of syphilis among older FSWs (7\%) - nearly two times higher among older FSWs compared to young FSWs. Older age is a risk factor of HIV and syphilis infection among FSWs in Nepal, and these results corroborate the results of other studies among FSWs [13-16].

The study had some limitations. IBBS surveys are cross sectional and thus cannot establish a causal association between the determinants and outcome. Moreover, it is possible that the same FSWs participate in multiple rounds of surveillance survey because the surveys are conducted in the same area among the same group over time.

\section{Conclusions}

This study suggests that older FSWs are at particularly high risk of STI infections. The findings indicate a specific need of HIV and STI prevention interventions among older FSWs because they are at higher risk of HIV and syphilis infection. Considering the high-risk behaviours among older FSWs, future HIV prevention intervention needs to address the special needs of older FSWs. However, young FSWs should also be targeted by HIV prevention programs. The HIV prevention interventions should be designed and implemented targeting different age group of FSWs.

\section{Acknowledgements}

We would like to thank all the survey participants and IBBS survey data collection research agency and staff who helped directly or indirectly to carry out the survey. We express our gratitude to the National Centre for AIDS and STD Control (NCASC), Teku, Kathmandu, Nepal for permission to use data. We thank Prof. Don McNeil for supervising this research. This study was funded by a postdoctoral fellowship from the Research and Development Office of the Prince of Songkla University.

\section{Conflict of interest}

The author's declared no potential conflicts of interest with respect to the research, authorship, and/or publication of this article.

\section{References}

1. National Center for AIDS and STD Control. National Estimates of HIV Infections in Nepal 2015. Kathmandu, Nepal 2015.

2. Baral S, Beyrer C, Muessig K, et al. Burden of HIV among female sex workers in low-income and middle-income countries: a systematic review and meta-analysis. Lancet Infect Dis 2012; 12: 538-549.

3. Morrison L, Weiss H, Buve A, et al. Commercial sex and the spread of HIV in four cities in sub-Saharan Africa. AIDS 2001; 15: S61-69.

4. National Center for AIDS and STD Control. Integrated Biological and Behavioral Surveillance (IBBS) Survey among Female Sex Workers in Kathmandu Valley, Nepal, Round V. Kathmandu, Nepal 2015.

5. National Center for AIDS and STD Control. Integrated Biological and Behavioral Surveillance (IBBS) Survey among Female Sex Workers in Pokhara Valley, Round V. Kathmandu, Nepal 2015.

6. National Center for AIDS and STD Control. Integrated Biological and Behavioral Surveillance Survey (IBBS) among Female Sex Workers in 22 Terai Highway Districts of Nepal, Round IV. Kathmandu, Nepal 2009.

7. Chen Y, Latkin C, Celentano DD, et al. Delineating Interpersonal Communication Networks: A Study of the Diffusion of an Intervention Among Female Entertainment Workers in Shanghai, China. AIDS Behav 2012; 16: 2004-2014.

8. Hong Y, Li X. Behavioral studies of female sex workers in China: a literature review and recommendation for future research. AIDS Behav 2008; 12: 623-636.

9. Nemoto T, Iwamoto M, Colby D, et al. HIV-related risk behaviors among female sex workers in Ho Chi Minh City, Vietnam. AIDS Educ Prev 2008; 20: 435-453.

10. Dunkle KL, Jewkes RK, Brown HC, et al. Gender-based violence, relationship power, and risk of HIV infection in women attending antenatal clinics in South Africa. Lancet 2004; 363: 1415-1421.

11. Mbonye M, Nakamanya S, Nalukenge W, et al. 'It is like a tomato stall where someone can pick what he likes': structure and practices of female sex work in Kampala, Uganda. BMC Public Health 2013; 3: 741 . 
12. Buzdugan R, Halli SS, Cowan FM. The female sex work typology in India in the context of HIV/AIDS. Trop Med Int Health 2009; 14: 673-687.

13. Shen Z, Zhang C, Li X, et al. HIV-related Behavioral Risk Factors among Older Female Sex Workers in Guangxi China. AIDS Care 2014; 26: 1407-1410.

14. Zhou Y, Li X, Zhang C, et al. Rates of HIV, syphilis, and HCV infections among different demographic groups of female sex workers in Guangxi China: Evidence from 2010 national sentinel surveillance data. AIDS Care 2013; 25: 1433-1434.

15. Zhang C, Li X, Hong Y, et al. Unprotected sex with their clients among lowpaying female sex workers in southwest China. AIDS Care 2013; 25: 503-506.

16. Hao C, Liu H, Sherman SG, et al. Typology of older female sex workers and sexual risk for HIV infection in China: a qualitative study. Cult Health Sex 2014; 16: 47-60.

17. Sarkar K, Bal B, Mukherjee R, et al. Young age is a risk factor for HIV among female sex workers - an experience from India. J Infect 2006; 53: 255-259.

18. Sarkar K, Bal B, Mukherjee R, et al. Sex-trafficking, violence, negotiating skill, and HIV infection in brothel-based sex workers of eastern India, adjoining Nepal, Bhutan, and Bangladesh. J Health Popul Nutr 2008; 26: 223-231.

19. Silverman JG, Decker MR, Gupta J, et al. HIV prevalence and predictors of infection in sex-trafficked nepalese girls and women. JAMA 2007; 298: 536-542.

20. Limpakarnjanarat K, Mastro TD, Saisorn S, et al. HIV-1 and other sexually transmitted infections in a cohort of female sex workers in Chiang Rai, Thailand. Sex Transm Infect 1999; 75: 30-35.

21. Decker MR, McCauley HL, Phuengsamran D, et al. Sex trafficking, sexual risk, sexually transmitted infection and reproductive health among female sex workers in Thailand. J Epidemiol Community Health 2011; 65: 334-339.

22. Fang X, Li X, Yang H, et al. Profile of female sex workers in a Chinese county: Does it differ by where they came from and where they work? World Health Popul 2007; 9: 46-64.

23. Liao SS, Schensul J, Wolffers I. Sex-related health risks and implications for interventions with hospitality women in Hainan, China. AIDS Educ Prev 2003; 15: 109-121.

24. Tran TN, Detels R, Long HT, et al. HIV infection and risk characteristics among female sex workers in Hanoi, Vietnam. J Acquir Immune Defic Syndr 2005; 39: 581-586.

25. Damacena GN, Szwarcwald CL, de Souza PR, et al. Risk Factors Associated with HIV Prevalence among Female Sex Workers in 10 Brazilian Cities. J Acquir Immune Defic Syndr 2011; 57: S144-152.

26. Urada LA, Malow RM, Santos NC, et al. Age Differences among Female Sex Workers in the Philippines: Sexual Risk Negotiations and Perceived Manager Advice. AIDS Res and Treat 2012; 2012: 812635. 